\title{
From Neonatal to Fetal Neurology: Some Clues for Interpreting Fetal Findings
}

\author{
${ }^{1}$ Claudine Amiel-Tison, ${ }^{2} \mathrm{~J}$ ulie Gosselin \\ ${ }^{1}$ Paris V University, Saint-Vincent de Paul Hospital, Paris, France \\ ${ }^{2} \mathrm{~S}$ chool of Rehabilitation, Faculty of Medicine, University of Montreal, Canada \\ Correspondence: Claudine Amiel-Tison, Professor Emerita in Pediatrics, Paris V University \\ Saint-Vincent de Paul Hospital, 82 Avenue Denfert-Rochereau, 75674 Paris Cedex 14, France \\ Phone: 011331 58412045, Fax: 011331432612 50, e-mail: amiel-tison@ club-internet.fr
}

\begin{abstract}
A s early as possible, neonatologists try to identify neonates at risk of unfavorable neurodevelopmental outcomes. They are fairly reliable in predicting very poor outcomes as well as optimal outcomes. However, within these two extremes, the prediction still remains a challenge. I mmaturity of the neonatal brain constitutes a limit in itself. During decades with the growing knowledge of brain development, many methods have been developed for neurological assessment of the neonate. Neither of them applied alone was perfect in terms of clinical applicability, sensitivity, reproducibility and specificity.

The motor function is the first to provide the clinician with clues. Higher functions, in particular language and other cognitive functions, will develop later. However, recent researchers give credit to the brainstem for controlling exceedingly rudimentary learning-related cognitive-like activity. At present, the anticipation of late emerging developmental disabilities remains difficult even though early motor dysfunction has repeatedly been associated with a higher risk of intellectual or other learning disabilities. Despite our modest recent contribution to the domain of prediction, further studies on welldefined high risk populations with rigorous methodology that aim to demonstrate these links are still needed. Besides neurological observations, research is in process of including behavioral and stress/ reactivity measures; feasibility and benefits have to be demonstrated.

A t present, fetal neurology is supported by neonatal neurology. Obstetricians are wise enough to take from both methods described above the el ements they are abl e to transpose to fetal life. A comparative table of neonatal and fetal assessment is to be found elsew here. A s for neonatal neurology, the future of fetal neurology will have to rely on short- and long-term follow-up studies to define the predictive value of the chosen items. Obstetricians will have to be as patient as pediatricians, to work, step by step, towards defining optimality and impairment. They will have to be very careful when deciding to interrupt pregnancies; at the time being, such decisions are restricted to cases of very severe impairment. In line with the spectrum described above, they can expect to find more cases with moderate to mild abnormalities than cases with severe ones. H ow ever the most pleasant aspect for the echographer is to check fetal optimality. J ust as a new born infant categorized as at risk of brain damage is competent enough to demonstrate CNS integrity from birth, a high risk fetus will soon be competent enough to demonstrate CNS integrity before birth.
\end{abstract}

Keywords: Fetal neurology, neonatal neurology, neurological assessment, brain devel opment, brain injury, developmental disability.

\section{OBSTETRICIANS AND NEONATOLOGISTS: A COMMON GOAL}

A s early as possible, neonatologists try to identify neonates at risk of unfavorable neurodevelopmental outcomes. They are fairly reliable in predicting very poor outcomes as well as optimal outcomes. However, within these two extremes, the prediction still remains a challenge. A s the neuromotor system matures early and cranial expansion passively follows hemispheric growth, neurological assessment should be able to produce early markers to predict later outcomes based on neuromotor and cranial findings. For many years, obstetricians have worked toward the same objective by monitoring fetal well-being during pregnancy. They rely on technical advances, namely ultrasonography (US) which has lead to the following statement: "Fetal behavior can be defined as fetal activities observed or recorded with ul trasound equipment." [66, p 413] This definition recalls $A$ Ifred B inet's famous answer on being asked what intelligence was: "I t is what my test measures"!

In fact, the advent of US has led to a kind of revolution. One of us (CA T) cannot forget the emotion felt when observing a 2D -US fetal assessment and being offered by J ason B irnholz, a pioneer in obstetrical US, ${ }^{18}$ a picture of the perfect profile of a 5 month-old fetus named Patricia; it seems one would be able to recognize her 20 years later, based on her facial morphology and expression. A the same time, $\mathrm{H}$ ans Prechl t began to describe fetal movements with $2 \mathrm{D}-U \mathrm{~S} ;{ }^{61}$ he used to say that he would be able to recognize years later an individual's gait pattern based on the quality of his/her fetal movements assessed by 2D-US.

The advent of 3D-4D US constitutes a turning point in the exploration of intrauterine life. In 2005, one of us (CA T) was offered a private session on a 3D-4D US fetal assessment 
recorded in the last trimester of pregnancy by A sim K urjak. ${ }^{45}$ L ooking at this fetus moving was another exciting experience as such an observation shakes our own perceptions of intrauterine life. The qual ity of movement as well as the variety of facial expressions were striking: a calm fetus, with open eyes and an alert attitude, executing elegant finger and thumb movements. At that time, A sim K urjak was puzzled by the absence of the M oro reflex, and looked for an interpretation for this surprising finding in an otherwise typical fetus. It was quite likely that the absence of the Moro reflex was the consequence of the head being passively maintained by the uterine wall. A ctually, the influence of head stability on motor activity recal Is observations made by $A$ Ibert G renier on neonates more than 30 years ago: by providing support to the neonate's head, he made more organized movements possible, that were accompanied by the suppression of the Moro reflex and grasping, as well as an increased state of al ertness. ${ }^{31}$ This clinical research has provided insights into our understanding of the interaction between head control and motor activity within the first weeks of postnatal life. The idea that the fetal environment could have an impact on spontaneous motor activity fits in with the present conception of development, which is viewed as "a complex process in which genetically based and environmentally driven processes continuously interact." [36, p 1182] One of us (J G) further studied Grenier's original approach by designing a scoring system allowing for the collection of quantitative data. ${ }^{28}$ This integration of knowledge on pre- and postnatal behavior has evolved towards the attempt to build a shared clinical view on fetal neurology. ${ }^{9,10}$

\section{BRIDGING RESEARCH AND PRACTICE}

Exhaustive descriptions of the current knowledge on fetal brain maturation are now easily accessible to the clinician. ${ }^{22,41,66}$ N evertheless, a brief review may be useful to the reader (Fig. 1). The early stage of neural proliferation and neuronal migration ends by 22 to 23 postmenstrual (PM) weeks. Next, several important events take place: axon and dendrite sprouting, synapse formation, glial cell proliferation and myelination. These processes begin between 20 and 30 PM weeks and extend to 40 PM weeks or beyond. Programmed cell death is known to begin very early, as soon as neurons proliferate, most active between 20 to 31 PM weeks, decreasing soon after, to persist at a lower level all life long. Joseph Volpe's article, entitled "Subplate neurons-M issing link in brain injury of the premature infant?" ${ }^{\prime 0}$ introduced the importance of the subplate to pediatric literature in 1996. The subplate (SP) is a transient structure which emerges as early as 10 PM weeks, with a maximal volume and activity from 20 to 31-32 PM weeks (being thickest at around 29 PM weeks), located below the future cortical plate, in the space where the white matter will later develop. What is the function of this vanishing structure? The subplate is familiarly compared to a "waiting room" for any axonal routing to or from the cortex, used for a few weeks until target cells are ready. During the waiting period however, temporary afferents contribute to generate fetal behavior. ${ }^{42}$

Since 1996, extensive clinicopathological data have been provided to clinicians. ${ }^{15,17,35,38,54,71,72}$ A s in many other research fields, new imaging techniques have played a prominent role in these advances, $14,20,21,24,39,43,53,55,64$ demonstrating normal development and various types of brain impai rments according to gestational age (GA). Moreover, experimental data has recently provided new insights into the sensorimotor network; as an example, experiments on D rosophila embryos and larvae highlight the importance of sensory input for the development of the motor function. ${ }^{69}$ The impact of induced mutation eliminating the sensory function in the D rosophilia embryonic peripheral nervous system is expressed in different ways according to the stage of development. In the embryo, the impact is mainly on the ratio of forward/backward peristaltic motor patterns; however, normal head swings still allow normal hatching. Later on, in the larva, the motor behaviors are very abnormal with nearly exclusive backward instead of forward movements. M oreover, head swings, which normally disappear at this stage of development, remain present in the senseless larva. These findings suggest that sensory input is essential for proper functional development of motor circuits. Ghosh and Shatz ${ }^{27}$ have shown that sensory neurons in the human fetus are present as early as 22 PM weeks in the subplate. How ever, thalamocortical connections will be functional later on, when target neurons are present in the cortical plate.

\section{FETAL BRAIN DAMAGE IN RELATION TO MATURATIVE STAGES: SELECTIVE VULNERAB ILITY}

$M$ aturative processes, as summarized above, take place very quickly. These changes explain why, for instance, the same hypoxic-ischemic $(\mathrm{HI})$ event will have different consequences according to timing: a similar insult will result in a white matter injury (W M I) at 27 PM weeks and in a grey matter injury (G M I) at 39 PM weeks. M oreover, such $\mathrm{HI}$ brain damage will have the same result when occurring in utero or after birth; in other words $\mathrm{HI}$ will have identical consequences on a $28 \mathrm{PM}$ week fetus or on a 28 PM week preterm newborn. The main types of brain damage can be briefly described as follows.

\section{White Matter Injury}

W hite matter injury (W M I) is the predominant type of injury, occurring in fetal life or the postnatal period in preterm neonates. W M I is the leading cause of cerebral palsy (CP) of perinatal origin. The particular susceptibility of preoligodendrocytes to anoxia is consistent with abnormalities of myel ination found at 


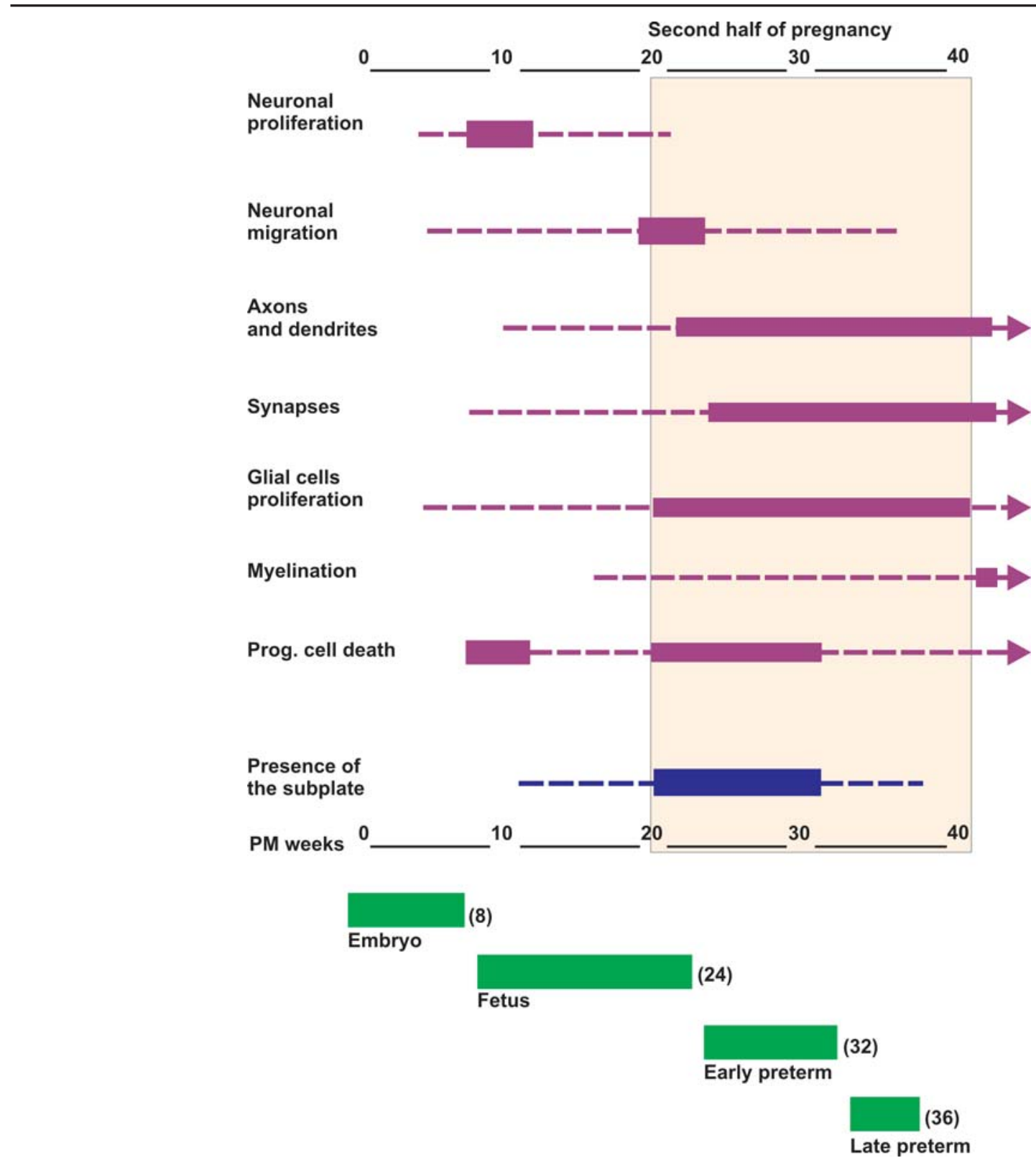

Fig. 1: Timetable of Brain Maturation up to 40 PM weeks Developmental process schematically represented up to 40 PM weeks (adapted from $22,41,66)$.

A dash-line means that the process is beginning or ending.

A bold line indicates the most intensive activity.

various degrees in this population. Fetuses and premature neonates share similar pathogenic mechanisms. If $\mathrm{HI}$ or materno-fetal infection occurs, the damage can be cystic periventricular leukomalacias (PVLs) or non cystic W M I injuries, focal or diffuse. The first type (cystic) is easily diagnosed by US and conventional M RI (and may therefore be identified in utero) whereas the second type (non cystic) can only be recognized by Diffusion Weighted Imaging (DWI). Recent studies reviewed by Back ${ }^{15}$ show: i) a spectrum of W M I including both types (cystic and non cystic), non cystic injury being of milder degree, and ii) a decline in the incidence of cystic PV L and a trend tow ard an increase in non cystic W M I.

\section{Gray Matter Injury}

Neuronal damage associated with W M I can now be identified with new imaging methods as reviewed by $\mathrm{V}$ olpe..$^{71,72}$ Quantitative Magnetic Resonance Imaging (M RI) shows reduced volume in cerebral cortical and deep nuclear structures. Cerebellar lesions are also revealed with quantitative M RI. ${ }^{50-52}$ 


\section{Subplate Neuron Injury}

This transient structure briefly described above shares with the germinative zone (GZ) the denomination of "vanishing structure". The SP is of the utmost importance for sensorimotor organization. W hat happens when SP neurons are damaged by $\mathrm{HI}$ ? Some of the consequences include the degeneration of waiting neurons deprived of their transient target and a lack of functional synaptic connections with the target neurons. If thalamic afferent axons fail to reach the cortex, sensory processing will be disrupted (see above, experimental senseless drosophilia). The cortical organization will be affected as well. B ecause of the transient nature of this structure, it will disappear anyway, normal or impaired, leaving predominantly a neuronal disorganization only detectable by functional neuroimaging. Such damage is probably the most common substrate for learning disabilities and behavioral problems in very tiny preterm infants.

\section{Anatomical and Clinical Correlations: E mergence of a Shared Spectrum}

Correlations between radiological and clinical data are both possible and important. The two approaches support the existence of a spectrum of abnormalities (Fig. 2). The spectrum of perinatal W MI, ranging from severe (cystic PV L) to moderate or mild (diffuse or focal lesions), is now accessible to neuroradiologists. ${ }^{15}$ The spectrum is also accessible to

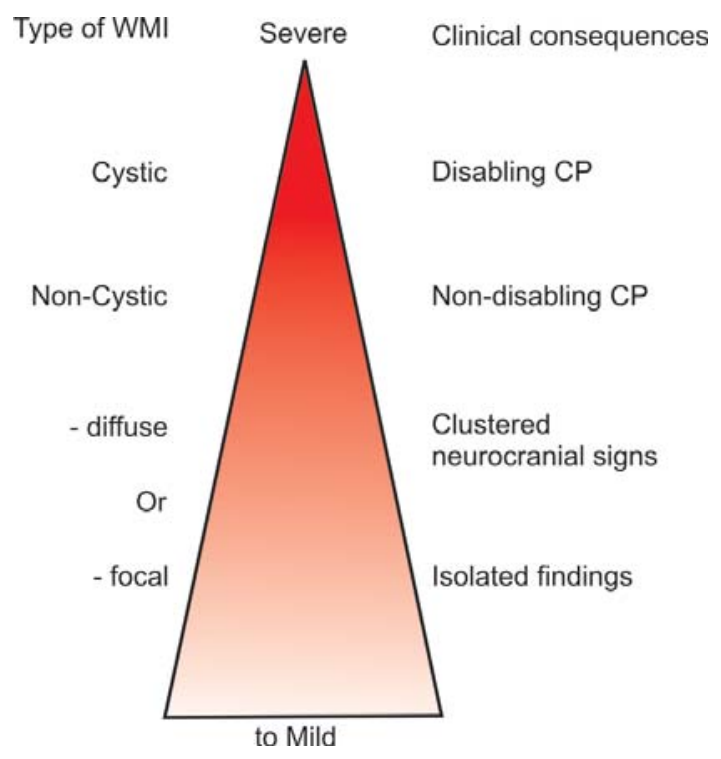

Fig. 2: Anatomoclinical correlations: a spectrum of WMI The pyramidal representation of this spectrum, shared by pathologists, radiologists and clinicians indicates that severe cases (cystic PVLs and disabling $(\mathrm{P})$ are less common than moderate and mild impairments (non cystic WMI and milder developmental dysfunction). clinicians: A 4-level categorization of neurological abnormalities at 2 years corrected age has been developed, ${ }^{7,29}$ going from CP (disabling or non-disabling) to minor neurocranial signs (clustered or isolated). Even though preliminary results based on this clinical spectrum are promising, ${ }^{7}$ more research using concomitant DWI and a structured clinical assessment is needed. Probably due to various factors, such as advances in perinatal care, imaging and standardized clinical assessment, a shift from severe damage to milder types of damage in the spectrum can be observed.

One particular situation remains to be elucidated: early fetal damage or postnatal damage in extremely low birth weight $(E L B W)(<1000 \mathrm{~g})$ infants may still be missed by clinical and radiological investigations if the lesions are mainly located in the "vanishing structures" (SP and GZ). Experience shows that the rate of disabling CP in this population is not much higher than in the population of very low birth weight (V L BW ) (1000$1500 \mathrm{~g}$ ) infants but a thorough disorganization expressed in the cognitive and behavioral functions is often identified later on. A lterations of the fetal motor function identified by 3D-4D US may provide the missing link in these cases.

\section{IMPACT OF INTRAUTERINE ENVIRONMENT ON FETAL MOTOR ACTIVITY}

\section{Head Stability Passively Maintained}

Grenier has demonstrated the essential role of head instability on motor behavior during the first post term (PT) weeks of life. ${ }^{31,32}$ In the experimental condition, manual support is given to the neck and spine while the infant's alertness and attention are solicited by the examiner: an amazing communication state is reached and facial expression becomes more diversified. At the same time, spectacular changes in motor behavior are observed: jerking movements, M oro and grasp reflexes disappear (an event termed "debugging"), flexor tone in the upper limbs decreases and the infant's hands open. For a short while, this particular state, called the "liberated state", allows the infant to intentionally reach and grasp an object (Figs 3 to 5). The significance attributed to this ability transiently obtained in an infant as young as 2 PT weeks is of high predictive validity: a positive response brings additional confirmation of the integrity of the upper system. ${ }^{28}$

Why does demonstration of this "liberated state" contribute to our understanding of fetal motor behavior? Because head stability passively maintained by the uterine wall during the second half of pregnancy obviously creates a permanent situation comparable to the head control transiently obtained postnatally during the experiment described above. M oreover, the facial expression observed during the experiment-calm, concentrated, totally involved in reaching the object proposedbears a very close resemblance to the facial expression and 


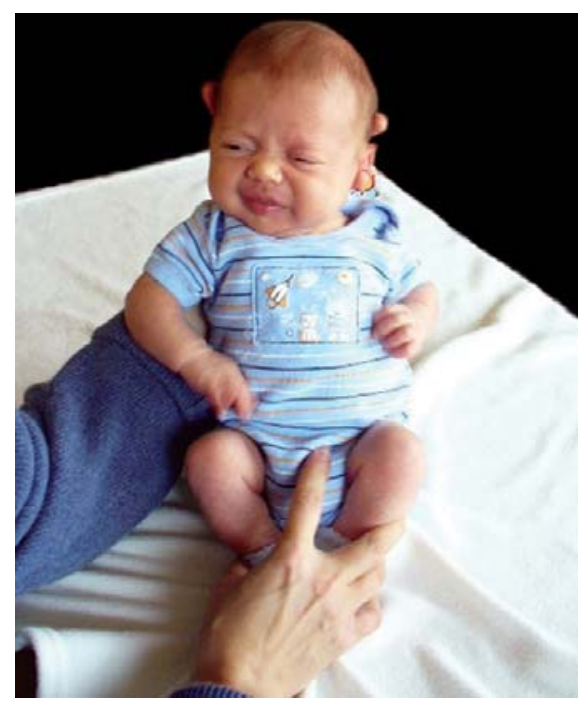

Fig. 3: Initial stage-variable state of alertness with quadriflexion of the limbs in a 10-day-old, full-term baby. Liberated state will be gradually achieved by soliciting the infant's attention while supporting the neck and spine.

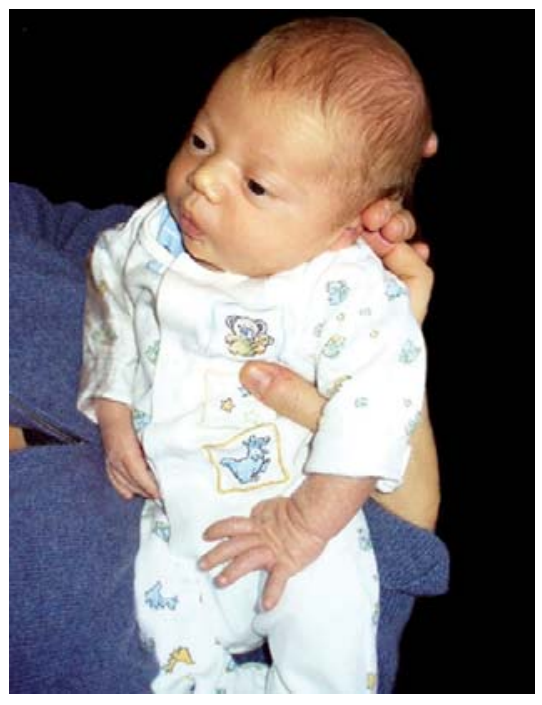

Fig. 4: Liberated state is characterized by amazing communication and peaceful facial expressions. Flexor tone in the upper limbs decreases and the infant's hands open.

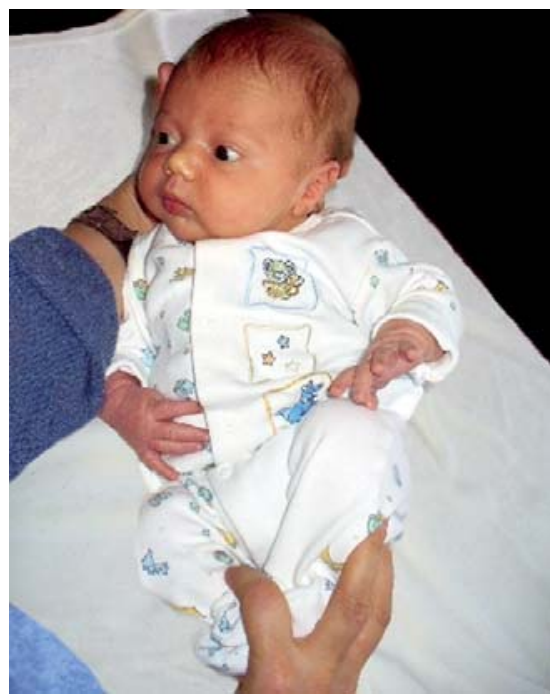

Fig. 5: Liberated state involves transient suppression of jerking movements, and Moro and grasp reflexes. The infant is open to intense interaction and facial imitation. Intentional reaching can be observed. attitude of the fetus manipulating its umbilical cord on the midline. In addition, the natural and prolonged "liberated state" of the fetus hel ps to explain the absence of the $M$ oro and grasp reflexes in utero, as routinely observed by 3D-4D US. ${ }^{44-46}$

It is tempting to speculate on these observations:

1. The fetus is very well protected, including against itself: even though the amount of W harton's jelly can protect the umbilical vessels, they are more secure if the grasp reflex is somew hat absent due to head stability in utero. The same remark applies to the M oro reflex, which could be a nuisance if repeatedly induced by any postural changes.

2. Postnatally, the young infant will have a much less "comfy" life from birth until the acquisition of head control, around 6 to 8 PT weeks. Physiological hyperexcitability and very active primary reflexes are well-known transient characteristics during the first 3 months of life. When tested in the parent's presence, emotion peaks when the new born begins to walk automatically, precompetence reminiscent of the evolution since homo erectus, ${ }^{2}$ even though this archaic performance cannot be considered useful for the newborn infant or for the neonatologist.

\section{Freedom from Gravity}

L ong before the availability of US, Liley ${ }^{49}$ commented on the differences between fetal and postnatal motor behaviors. For example, he explains the ability to roll over early during fetal life but not from birth to 14 to 20 PT weeks as "... a trick which is simple in a state of neutral buoyancy [which] becomes difficult under the new-found tyranny of gravity". A t the first minute of postnatal life, the most spectacular response ready to counteract gravity is the full righting reaction observed when the neonate is placed in the upright position: tactile stimulation of the sole of the feet provokes an active response in the extensor muscles; body weight is then actively sustained for a few seconds. As developed below, this response depends on the brainstem (lower motor system) and therefore evolves with the subcortical structures in a caudocephalic wave (with a response restricted to the lower limbs around 28 PM w eeks and reaching the head by 38-40 PM weeks). During fetal life, verticality is not at all necessary to elicit the activity of the antigravity muscles: the contact of the soles with the uterine wall stimulates the extensor muscles of the axis, whatever the fetal position is. A large repertoire of fetal movements is possible including trunk rotation due to the freedom from gravity. M oreover, the constant vestibular stimulation coming from both the fetus itself and the mother's movements probably contributes to the early maturation of the vestibular system ${ }^{19}$ (Fig. 6) (The five cranial nerves with nuclei located in the brainstem (VIII to XII) are mature by 34 PM weeks, i.e. earlier than the ones issued from the pons and midbrain).

M otor acquisitions will appear in the first year of life as a consequence mainly of upper motor system maturation. The infant will successively acquire head control, independent sitting and independent walking, in a descending maturative wave. Incidentally, it is remarkable to observe how the motor system is al ready well prepared for protection of the infant at each new victory over the "tyranny of gravity". N ew postural reactions occur, such as the lateral propping reaction to maintain a sitting position and, later, the parachute reaction, ready to attenuate bad falls while learning to walk. ${ }^{6,29} \mathrm{H}$ owever, in the first 6 to 8 


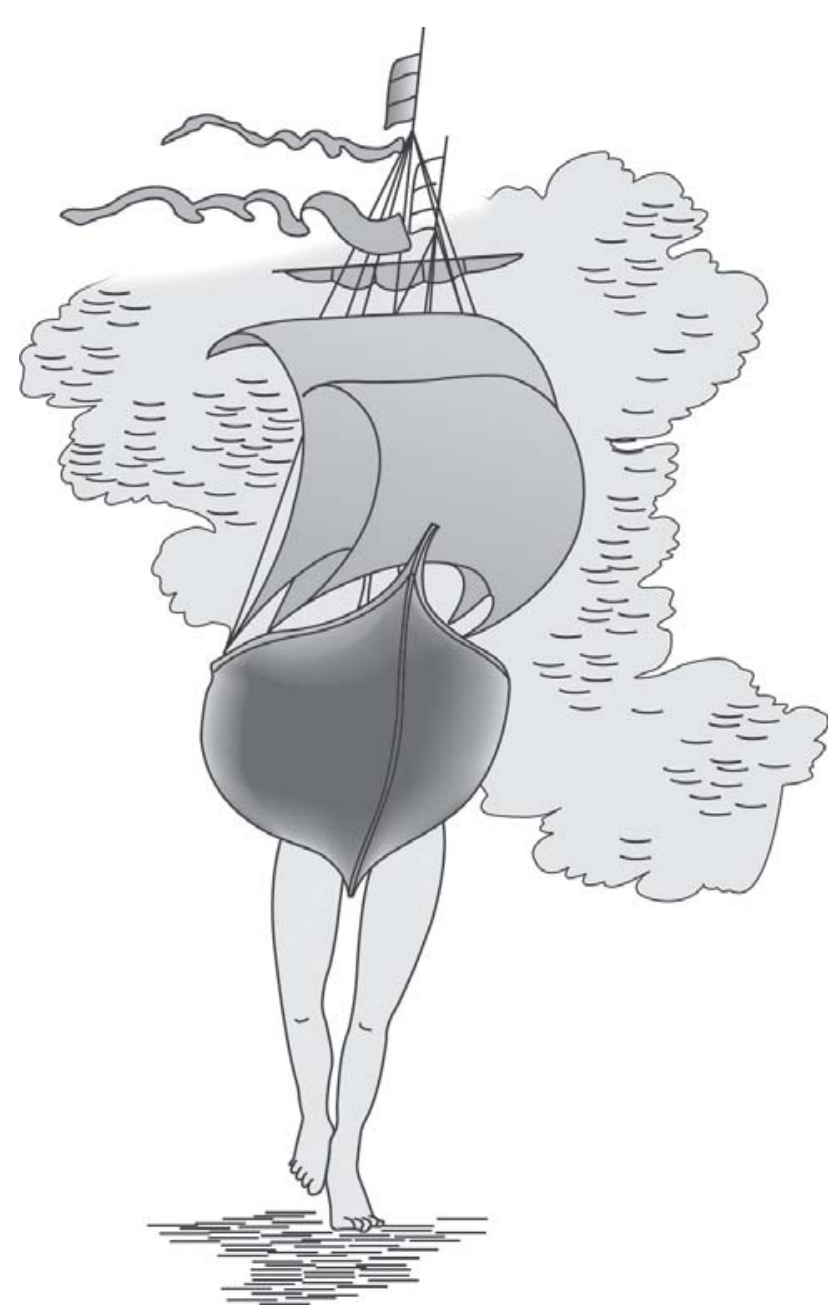

Fig. 6: Fetal Navigation

Fetuses are passively rocked in their mother's womb: a long cruise followed by sudden stillness when they land. (from ref 11 with permission)

PT weeks, the infant seems to be powerless against gravity; the infant is no longer able to move as was possible in utero. Head control will represent a turning point in the expression of motor activity. Such an understanding of these sequential stages will have to be considered in any early assessment of the neuromotor function.

\section{NEONATAL NEUROLOGICAL ASSE SSME NTS}

\section{Two Schools, Two Methods}

Neurological assessment of the neonate has many facets, continuously evolving according to neurophysiological advances. We will briefly describe two approaches, in other words, two schools: one is the French school initiated by A ndré Thomas and Saint-A nne Dargassies in the fifties. ${ }^{13,65}$ The proposed method is based on an assessment of muscle tone and reflexes, a method inherited by one of us (CAT) in the sixties, which was later transmitted to J ulie G osselin. R ecent work has focused on the standardization of the assessment. 4,5,30 This tendency represents the so-called "classical method". The other method from the $\mathrm{N}$ etherland school, initiated by Prechtl. ${ }^{61,62}$ in the eighties, is based on observing the quality of spontaneous movements. This approach promotes a "change of paradigm from the traditional testing of reflexes and responses to an assessment technique that systematizes the observation of the quality of spontaneous movements [... which represents] a breakthrough in the functional assessment of the young nervous system." [35, p 62]. A high degree of parochialism is easily perceptible in the literature; we must choose the church we want to belong to... A short description of both types of assessment will be presented here prior to a demonstration of their common goal: to focus on upper motor control, which changes along with brain maturation.

\section{The Amiel-Tison Assessment at Term: Based on Tone Changes}

\section{Physiological Foundations}

A ndré-Thomas was fascinated by brainstem activity, which is so conspicuous in the term newborn infant due to the maturational stage. He defined passive and active tone and considered deviance from the expected tone changes according to maturation to be of valuable significance. ${ }^{13}$ As a young neonatologist in the early 1960s, one of us (CAT) had the opportunity to train under his protégée, Saint-A nne D argassies, assessing neonates in Port-R oyal-B audelocque Hospital in Paris. At that time, this researcher was accumulating data on the ascending wave of maturation from 28 to $40 \mathrm{PM}$ weeks. ${ }^{65} \mathrm{At}$ the same time in Germany, Peiper ${ }^{60}$ was publishing an exhaustive description of the performances revealing cerebral functions in the full term newborn. He described a descending wave of maturation of the upper control system occurring in the first years of life.

It was not until the 1980s, when Harvey Sarnat ${ }^{68}$ reviewed anatomical and physiological experiments by Lawrence and Kuyppers ${ }^{47,48}$ that pediatricians became fully aware of the clinical significance of their observations. ${ }^{1,4-6}$ It then became possible to clinically demonstrate the individual development of both upper and lower motor control systems: i) the lower system, consisting of the brainstem and cerebellum, matures early (becoming accessible to clinical assessment at about 28 PM weeks) in an ascending wave and its essential role is to maintain posture against gravity and flexor tone in the limbs; ii) the upper system, consisting of the cerebral hemispheres and basal ganglia, matures later (clinically emerging at 34 PM weeks) and rapidly for the first 2 years in a descending wave and its essential role is to control the lower system, with relaxation of the limbs and control of the antigravity forces, finally allowing erect posture, walking and fine motor skills (Fig. 7). This distinction became even more relevant after 
pathological and radiological data had shown that brain damage in the neonate is mainly located in cerebral hemispheres, in the full term infant with hypoxic ischemic encephalopathy (HIE) or in the premature new born with periventricular leukomalacia
(PVL) and other types of WMI. Consequently, the best predictors of impairment are found in responses that depend on the upper control system and not in the responses that depend mainly on brainstem activity.

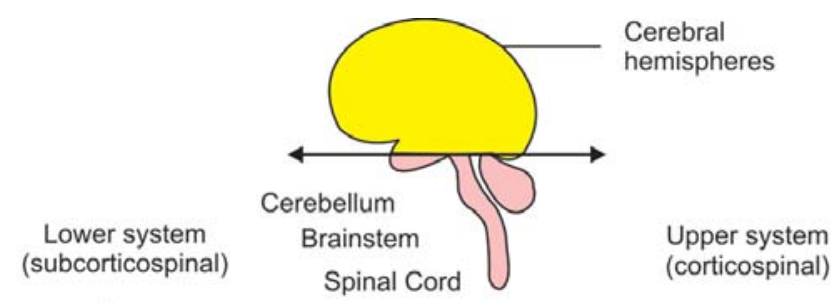

A

B
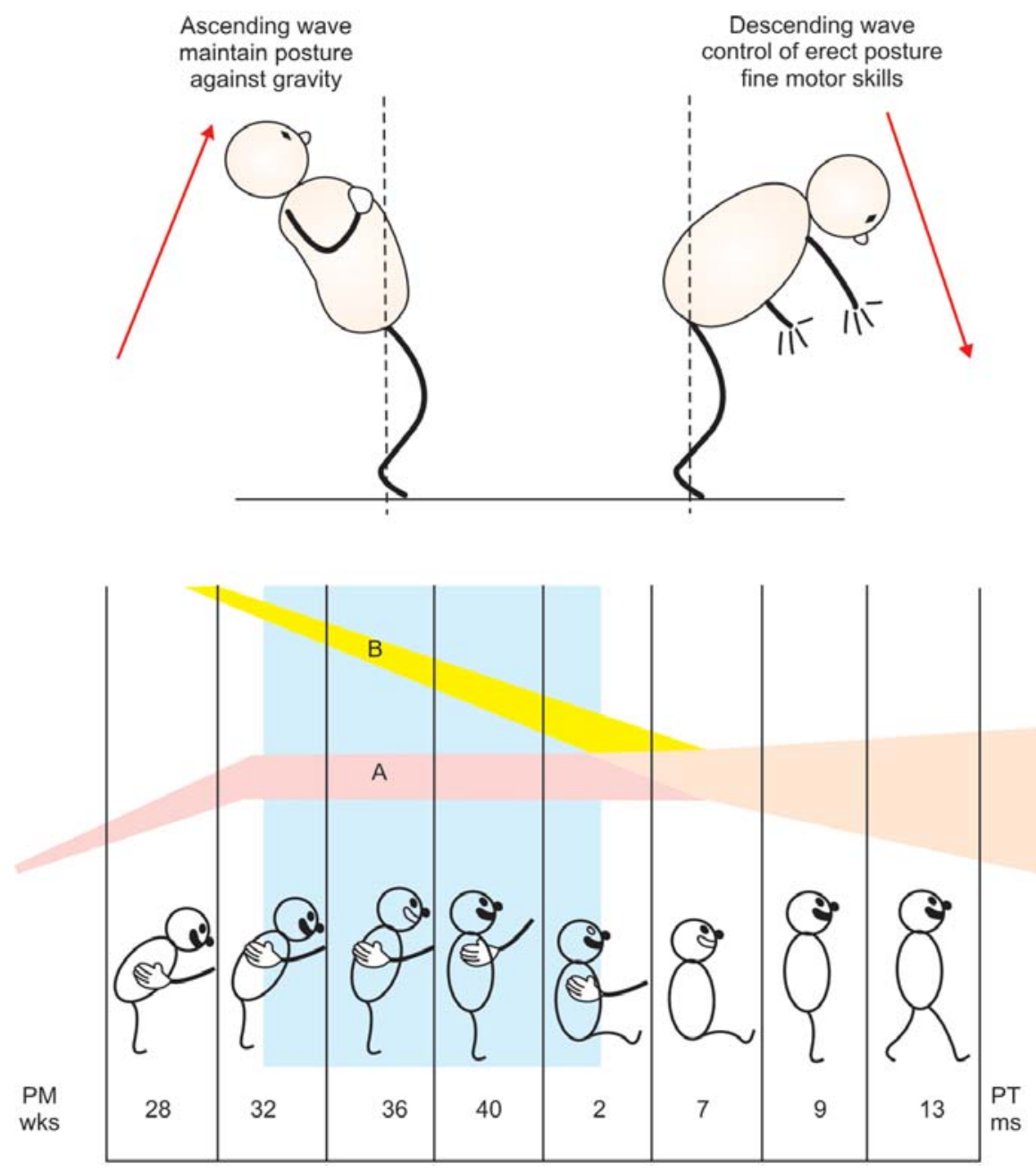

Fig. 7: Maturation in motor control from fetal life through infancy

The subcortical pathways (lower system or extrapyramidal, A) derive from the brain stem with maturation proceeding upward, starting in the spinal cord. Their essential role is to maintain posture against gravity. The corticopsinal pathways (upper system or pyramidal, B) originate in cerebral hemispheres. Their maturation starts later, proceeds downward from the pons to the spinal cord. They are responsible for control of erect posture and for movements of the extremities including fine motor skills. From term onward, corticospinal control takes over, allowing development of mature head control, sitting and walking. The transition period is in blue. 


\section{Elaboration of a Clinical Assessment}

These pathophysiological considerations have been the driving force for successive modifications of the clinical assessment at term. M ore emphasis has been placed on signs that depend on the integrity of the upper structures, such as axial tone and alertness, as well as cranial signs linked to theincrease in volume of the cerebral hemispheres. The signs depending on brainstem function, such as primitive reflexes and passive tone in limb flexor muscles have been de-emphasized at the neonatal period as they do not provide information about the cerebral hemispheres and basal ganglia. To gain a more precise definition of infant response, a three-point scale has been devised for each item: 0 normal; 1-moderately abnormal; 2-abnormal. The scoring system has been standardized for application beginning with the full term newborn ${ }^{5}$ and continuing up to school age in order to have methodological consistency from birth to 6 years. ${ }^{7,29}$

Evaluation of head growth and identification of cranial signs are an important part of the assessment. A dramatic increase in brain volume occurs in fetal life and the first two years after term birth. Concomitantly, the skull follows the volumetric increase of the cerebral hemispheres mostly by passive adaptation. The relationship between head and brain growth explains why the classical neurological assessment in infancy universally includes measurement of head circumference $(\mathrm{HC})$. However, this crude information which derives from $\mathrm{HC}$ measurement remains insufficient to qualify brain growth. Significant information with respect to the
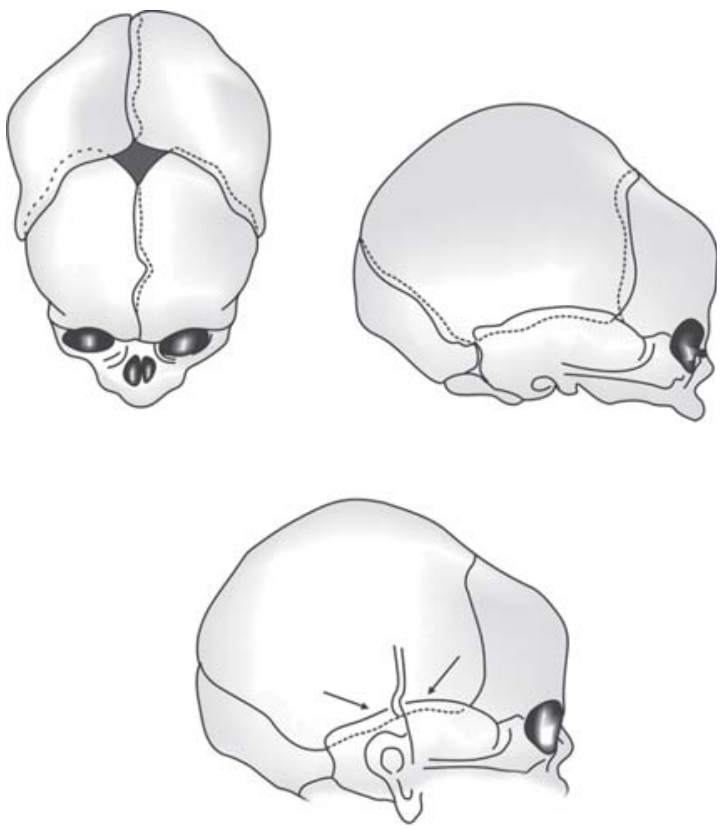

Fig. 8: Cranial sutures

In case of severe cerebral atrophy, ridges are perceived on every sutures, due to overlapping of cranial bones. In mild to moderate cases, a ridge is only present above the ear, when edge of temporal bone is overlapping parietal bone (squamous ridge). integrity of the underlying cerebral hemispheres can be provided by systematic palpation of the main cranial sutures. In severe cases, every suture is involved, with overlapping being perceived as a ridge. In mild and moderate cases, the squamous suture is particularly informative due to its strategic location at the junction of the cranial vault and the cranial base. ${ }^{8}$ B eing located between the parietal and temporal bones, it can be felt by palpation just above the ear. The overlapping of this suture has been proposed as a marker of moderately decreased brain growth (Fig. 8).

Passive tone is examined by evaluating the amplitude of slow passive movements (i.e. extensibility of muscles) carried out by the observer when the infant is at rest. Passive tone in the limbs evolves upward from hypotonia up to 28 PM weeks to hypertonia, the normal physiological status at term birth. With brainstem maturation the changes are so fast that one has to define hypo or hypertonia with strict reference to the normal finding at a given PM age. Passive tone in the axis is eval uated by comparing amplitude of passive flexion and passive extension. In the typical situation, at any age, flexion exceeds extension; the reverse pattern is abnormal, as well as unlimited flexion and extension.

Active tone refers to active movements of the infant in reaction to certain situations imposed by the examiner. ${ }^{30}$ Three responses are elicited by the following items: i) the active global righting reaction in the upright position; ii) active passage of the head forward during the raise to sit maneuver (Fig. 9); iii) active passage of the head backward during the back to lying

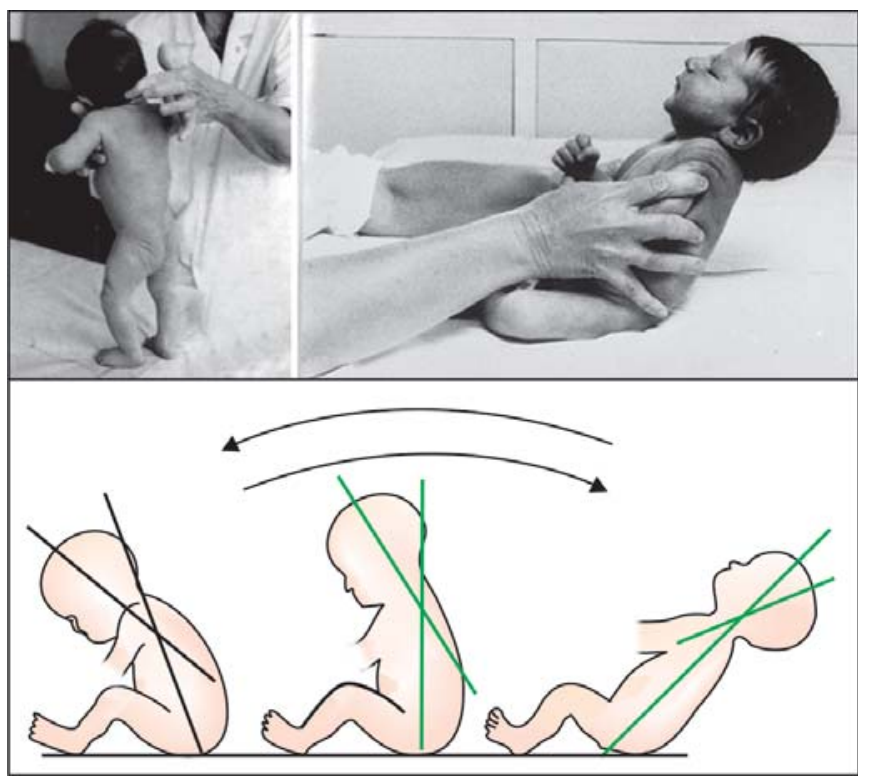

Fig. 9 Active tone: reaction tested to situations imposed by the examiner

Global righting reaction in the upright position

Active passage of the head forward during the rise-to-sit maneuver Active passage of the head backward during the reverse maneuver. 
maneuver. These three responses permit analysis of the antigravity forces (lower system) and the control exerted on these antigravity forces by the upper system. The correct technique for each of these three manoeuvres is described el sewhere. ${ }^{4}$

Spontaneous motor activity is scored on a three-level scale according to both quantitative and qualitative aspects as well as symmetry right/left. Our scoring system (Table 1), is issued from a gestalt approach throughout the neurological assessment. A ttention is given to hand opening, independent finger movements, and, above all, to active thumb abduction, as this ability at term is possible only if the upper system is intact.

Table 1: Spontaneous motor activity at 40 PM weeks. Scored 0, 1, 2 for right and left side

\begin{tabular}{lll}
\hline Spontaneous motor activity & & \\
V aried, harmonious & 0 & \\
Insufficient, stereotyped & 1 & \\
A bsent or barely present & 2 & $\mathrm{~L}$ \\
A symmetrical (pathological side) & $\mathrm{R}$ & \\
\hline Spontaneous thumb abduction & 0 & \\
A ctive thumb & 2 & \\
Inactive thumb & 2 & \\
Fixed thumb in adduction & $\mathrm{R}$ & $\mathrm{L}$ \\
A symmetrical (pathological side) &
\end{tabular}

P rimary reflexes are measured by examining a few of them, with particular emphasis on non-nutritive sucking, which is systematically evaluated. Palmar grasping, M oro reflex and automatic walking are considered as adjuncts where unilateral damage is suspected or to confirm CNS depression.

Alertness is evaluated by examining visual fixation and pursuit, quality of sucking and social interaction. When abnormal, hypoactivity, hypotonia, and lethargy will indicate whether the CNS depression is mild/moderate or severe. The excellent inter-observer reliability for the final synthesis was confirmed (kappa coefficient $=0.76) .{ }^{23}$

\section{Clinical Synthesis}

Final synthesis following the analytical evaluation is based on the clustering of signs and symptoms. When every response is optimal (score 0 ), the probability of a favorable outcome is high. This means that hemispheric growth, alertness/ communication, motor control and adaptability are typical of a full-term neonate (Table 2).

When responses are not optimal (score 1 or 2 ), neurological status can be graded into three categories for full term infants and two categories for preterm infants.

In the full-term neonate (Table 3), three grades of severity can be defined at the end of the first week:

- Mild: A bnormalities of tone hyperexcitability, no C NS depression, no seizures.

- M oderate: A bnormalities of tone, signs of C NS depression, rare or isolated seizures (up to two).

- Severe: Repeated seizures and overt C NS depression.

Repeated assessments in the first week of life will differentiate between two profiles: when signs of CNS depression and tone abnormalities are unchanged from assessment to assessment, the clinical profile is defined as unchanging. This particular clinical profile may indicate a prenatal insult. In this case, three neurocranial signs (Fig. 10) monitored within the first days of life represent essential and specific clues when dating brain damage as prenatal in a full term neonate: a high-arched palate (the result of insufficient tongue movements during fetal life), non-reducible adduction of thumbs in a tightly clenched fist, and suture ridges. ${ }^{3}$ These signs are not specific per se; they must be already present at birth if they are to be interpreted as having antenatal origins. A recent study confirmed the value of these signs in assessing the etiology and timing of brain lesions. ${ }^{58}$

Table 2: Clinical criteria defining optimality of CNS function at term

\begin{tabular}{|c|c|c|c|}
\hline Observations or tests & Optimal responses & & Significance \\
\hline Head circumference $\mathrm{cm}$ & Same range as birth weight ( \pm 25 centiles) & $x$ & \multirow{2}{*}{ Adequate hemispheric growth } \\
\hline Cranial sutures & Edge to edge (squamous included) & $x$ & \\
\hline V isual pursuit (Fix and track) & Easily obtainable & $x$ & \multirow{3}{*}{ No CNS depression } \\
\hline Social interaction & Eager & $x$ & \\
\hline Sucking reflex & Efficient, rhythmic & $x$ & \\
\hline Raise-to-sit and reverse & A ctive flexor muscles (balance with extensor muscles) & $x$ & \multirow{4}{*}{ Upper motor control integrity } \\
\hline Passive axial tone & More flexion than extension & $x$ & \\
\hline Passive tone in limbs & Symmetrical and within normal limits for $\mathrm{GA}$ & $x$ & \\
\hline Fingers and thumbs & Independent movements and abduction of thumbs & $x$ & \\
\hline
\end{tabular}

*A NS: A utonomic N ervous System 
Table 3: Summary of the assessment for term newborn infants

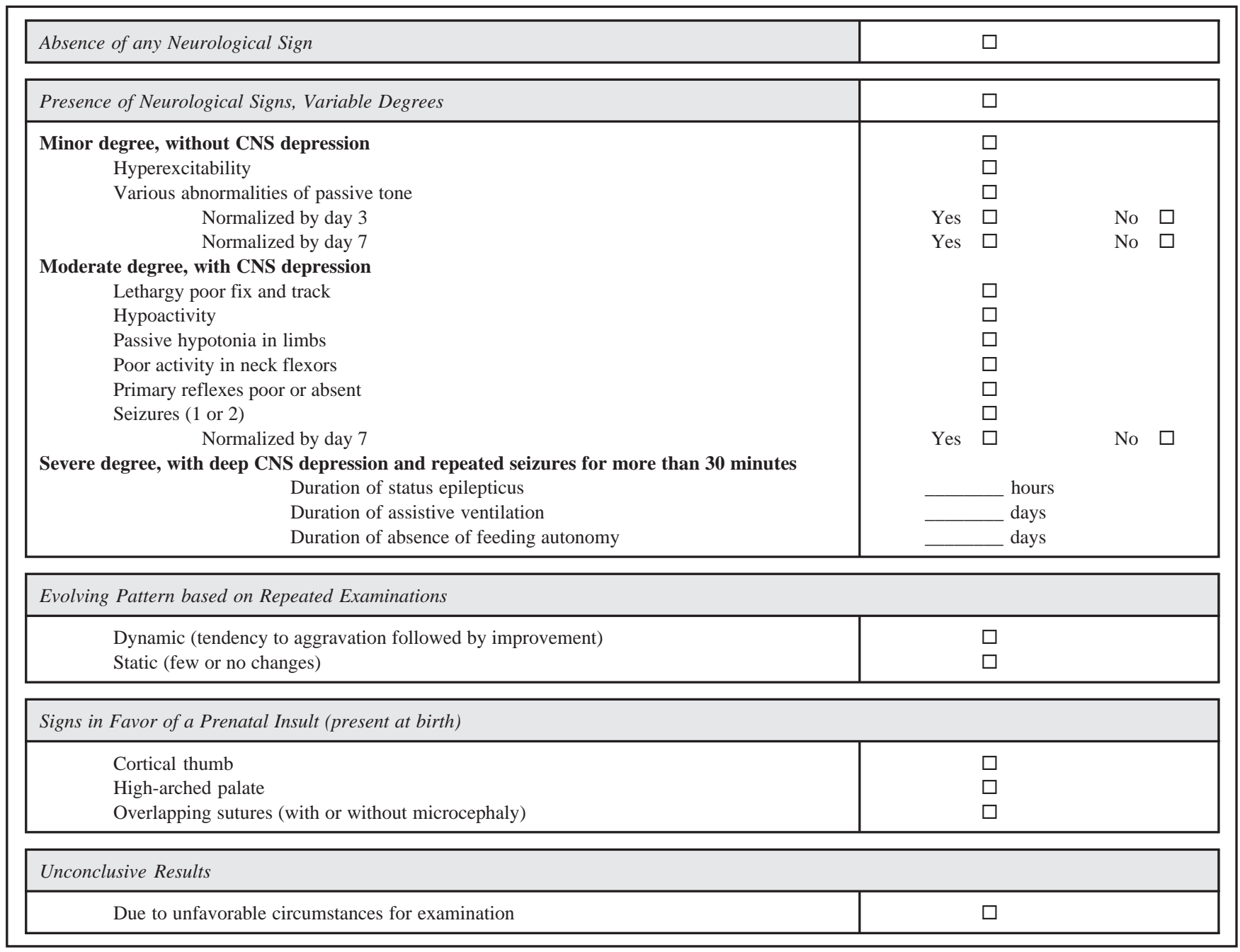

On the other hand, when signs of CNS depression increase up until day 3 and then tend to get better with progressive improvements in alertness, motor activity and sucking, the clinical profile is defined as changing. This changing profile is typical of a very recent insult, most often intrapartum.

In the preterm infant, when neurological and/or cranial signs are found around $40 \mathrm{PM}$ weeks, conclusions should take into account extra-neurological problems not yet completely resolved. The degree of severity will be limited to two levels: $\mathrm{mild} /$ moderate and severe.

\section{The Prechtl Assess ment, Based on Spontaneous motor Behavior}

Physiological Foundations

Prechtl and his followers proposed a conception of motor behavior which is understood as " the net result of the activity of complex spinal or brainstem machineries, which are subtly modulated by segmental afferent information and ingeniously controlled by supraspinal networks" ( $p$ 483). ${ }^{35}$ In other words, the young nervous system generates a variety of motor patterns originating in "neural networks that are able to coordinate autonomously (i.e. without sequential sensory or supraspinal information) the activity of many muscles" ( $p$ 483). ${ }^{35}$ The observation of pre- and postnatal spontaneous motor behavior drove Prechtl to describe general movements (GM s) as "series of gross movements of variable speed and amplitude, which involve all parts of the body but lack a distinctive sequencing of the participating body parts" ( $p$ 484). ${ }^{35}$

Due to the timing of neuronal maturation and the occurrence of $\mathrm{GMS}$, this motor pattern is considered as being produced without afferent information. "Remarkably, GM s are among the first movements that the human fetus develops, and they emerge prior to isolated limb movements. GM s can al ready be observed before the completion of the spinal reflex arc, which is accomplished at 8 weeks postmenstrual age (PM A)" ( $p$ 484). ${ }^{35}$ 

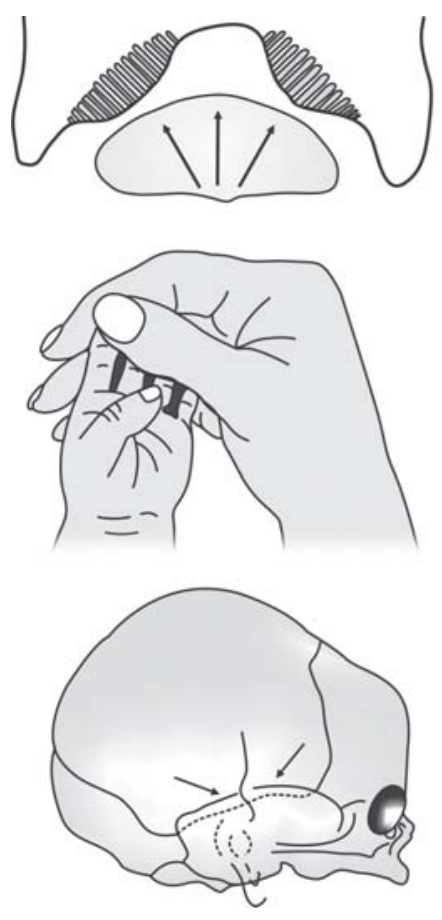

Fig. 10: Clues of a prenatal insult in the term infant High-arched palate (insufficient molding forces of the tongue) Adductus thumbs in a clench fist (absence of spontaneous abduction) Cranial ridges (due to impaired hemispheric growth) (adapted from ref 3).

A review of experimental evidence of endogenously generated motility can be found el sewhere. ${ }^{26} \mathrm{GM}$ s show agespecific characteristics (Table 4) with increasing variation, movement direction, amplitude, speed and complexity.

Prechtl and colleagues propose a sequence in the acquisition of these different GM s (preterm, writhing, fidgety) with overlaps. The "fidgety" GM s disappear around 4 months post term, being gradually replaced by goal-directed movements. Such a conception of the organization of motor behaviors relies partly on the synchrony of fetal brain maturation and the timing at which functional changes occur. In a recent paper, ${ }^{36} \mathrm{H}$ addersA I gra has attempted to correlate some specific features of $\mathrm{GM} \mathrm{S}$ and neuromaturative phenomena. These correl ations are mainly based on the "coincidence of emergence":

- During the third trimester of pregnancy: Improvement in movement complexity and variation and the emergence of synaptic activity in the subplate;

- Near term: Emergence of "writhing GM s" and changes in cortical neurotransmitter systems.

\section{Elaboration of a Clinical Assessment}

Prechtl's initial clinical studies came with the advent of advanced ultrasound equi pment which made possible prolonged and repeated direct observations from 7 to 8 PM weeks onwards. Continuous one-hour recordings are made and stored on videotape for off-line analysis. A s for the ex utero examination, a video camera is installed high above the infant who is lying supine in the incubator or bed. Recordings are made while the infant is in state of alertness 3 and last between 30 and 60 minutes in order to collect about three GM s. L ater on, recordings are viewed at high speed and GM s are then appraised on a visual gestalt perception of the spatial and temporal variation of motor patterns. ${ }^{36}$ The interjudge and intrajudge reliabilities are considered to be excellent, with $\mathrm{K}$ appa values around 0.80 achieved after 2 days on site-training and further practice of about $100 \mathrm{GM}$ recordings.

The in utero assessment has permitted a description of the fetal motor repertoire, and demonstrates the influence of GM s on changes in fetal posture: the contact of the feet on the uterine wall resulting from $\mathrm{GM} s$ and alternating leg movements provoke changes in the intrauterine position in utero. From 36-38 PM weeks until the end of the second month post-term, the repertoire changes and GM s are commonly referred to as writhing movements, characterized by small to moderate amplitude and slow to moderate speed. They are ellipsoid in form, which creates the impression of a writhing quality. By 2 months post term, they gradually disappear and fidgety GM s gradually emerge: small movements in all directions of moderate speed and variable acceleration involving the neck, trunk and limbs; they last until 20 PT weeks. A temporal overlap can be observed as shown in Table 4.

Table 4: Age-specific characteristics of normal GMs (from ref 35, with permission)

\begin{tabular}{|c|c|c|}
\hline GM type & Period of presence (weeks PMA) & Description \\
\hline Preterm GM s & From $\pm 28 w$ until $36-38 w$ & Extremely variable movements, including many pelvic tilts and trunk movements \\
\hline Writhing GMs & Form $36-38$ w until $46-52$ w & $\begin{array}{l}\text { The variable movements take on a more forceful ("writhing") character. In comparison } \\
\text { with preterm GM s, "writhing" GM s seem to be somewhat slower and to show less } \\
\text { participation of the pelvis and trunk }\end{array}$ \\
\hline Fidgety GM S & From $46-52$ w until 54-58 w & $\begin{array}{l}\text { Basic motility consists of a continuous flow of small and el egant movements occurring } \\
\text { irregularly all over the body, i.e. head, trunk, and limbs participate to a similar extent. The } \\
\text { small movements can be superimposed on large and fast movements. }\end{array}$ \\
\hline
\end{tabular}

At any GM age, the basic characteristics of normal GM s are: (i) participation of all body parts and (ii) movement complexity and variation. 


\section{Clinical Synthesis}

If the nervous system is impaired, GM s lose their complex and variable character. Different types of abnormal patterns may be recognized and clustered into different age-specific categories: ${ }^{26,34}$

- Poor repertoire when the sequence of the successive movement components is monotonous and movements of the different body parts do not occur in the complex way seen in normal GMs.

- Cramped-synchronized GM s are considered to be abnormal from preterm age onwards. These cramped-synchronized GM s refer to rigid movements lacking the normal smooth and fluent character; all limb and trunk muscles contract and relax al most simultaneously. If this abnormal pattern is observed consistently over a few of weeks it is of high predictive value for the devel opment of spastic CP. ${ }^{25,35}$

- Chaotic GM s of all limbs are of large amplitude and occur in a chaotic order without any fluency or smoothness. Infants with chaotic GM s often develop cramped-synchronized $\mathrm{GM} s$ a few weeks later.

- Abnormal fidgety movements look like normal fidgety movements but their amplitude, speed and jerkiness are moderately or greatly exaggerated.

- Absence of fidgety movements is concluded when movements are never observed from 9 to 20 PT weeks; this absence is highly predictive for later neurological impairment. Predictive value at both extremes of the spectrum is good: cramped synchronized $\mathrm{GM} s$ are highly predictive of $\mathrm{CP}$; normal repertoire is highly predictive of an optimal outcome. However, in between, the group of infants with a poor repertoire will later split into normal, subnormal or severely damaged subgroups. ${ }^{26}$

\section{Similarities and Differences}

In the upper section of Table 5, similarities are analyzed. In the lower section, differences are highlighted. As far as reliability and predictive value are concerned, both methods are comparable. ${ }^{59}$ However, both methods face the same chall enge in intermediate situations, for which outcomes remain difficult to establish before a more advanced level of neuromaturation. As for the method itself, the "hands off" observation of GM s as proposed by Prechtl has an obviously invaluable advantage for fetal 3D-4D observations as well as for very sick infants. On the other hand, such a distance between the examiner and the infant may represent a significant source of frustration for pediatricians. The latter may be more comfortable with the "hands on" situation proposed in the classical examination, which creates interaction between examiner and examinee. The infant's behavior is relational, as proposed by Neisser, ${ }^{57}$ continued participation and mutuality betw een the neonate and the examiner is experienced daily by "hands on" clinicians (Fig. 11). M oreover, such contact may allow for a better appraisal of the different alertness states as well as the fluidity of changes. Finally, encompassing the first 6 years of life, the classical assessment provides methodological continuity, continuity of the utmost importance in the course of any follow-up.

Table 5: Similarities and differences between the ATNAT and the GMA

\begin{tabular}{|c|c|c|}
\hline Characteristics & ATNAT & GMA \\
\hline Duration of assessment & \multicolumn{2}{|c|}{ Comparable } \\
\hline Interobserver reliability & \multicolumn{2}{|c|}{ Similar } \\
\hline Predictive value & \multicolumn{2}{|c|}{ Similar } \\
\hline For disabling CP & \multicolumn{2}{|c|}{ Good } \\
\hline For non-disabling CP & \multicolumn{2}{|c|}{ Poor } \\
\hline For optimality & \multicolumn{2}{|c|}{ Good } \\
\hline
\end{tabular}

Identification of prenatal damage

Comparable

Type of assessment

Feto-neonatal continuity

Continuity in the course of follow-up

\begin{tabular}{l|c} 
Hands-on & Hands-off \\
No & Y es \\
Y es (6 years) & No
\end{tabular}

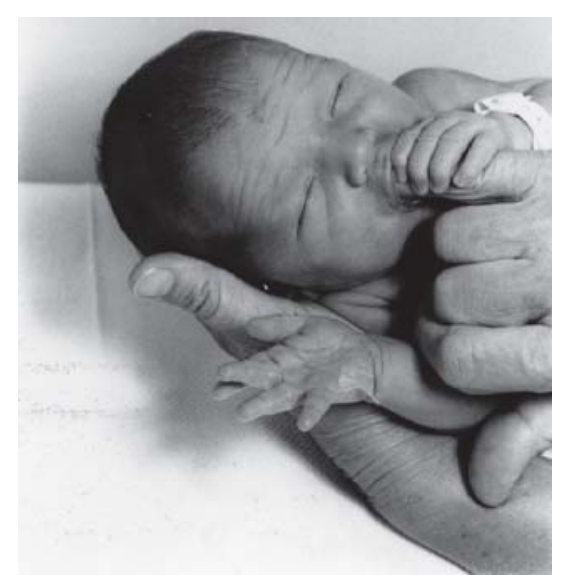

Fig. 11: A 2 days old baby girl

She is self quieting at the end of the assessment: peaceful recovery, holding on the midline and sucking the examiner's finger.

The two methods differ as regards with the specific manoeuvres or signs used to test the integrity of the different neuro-pathways (Fig. 12). Spinal and brainstem control are omnipotent until 34 PM weeks or so. A transitional period follows during which corticospinal control progressively becomes preponderant. H ead control is a very important marker, accompanied by the decrease of primary reflexes and smoother motor activity, making life more comfortable around 8 to 10 PT weeks. Later on, the corticospinal power over lower structures will advance, allowing gross and fine motor acquisitions. However, both methods explore subcorticospinal as well as corticospinal control, both recognize a transitional 


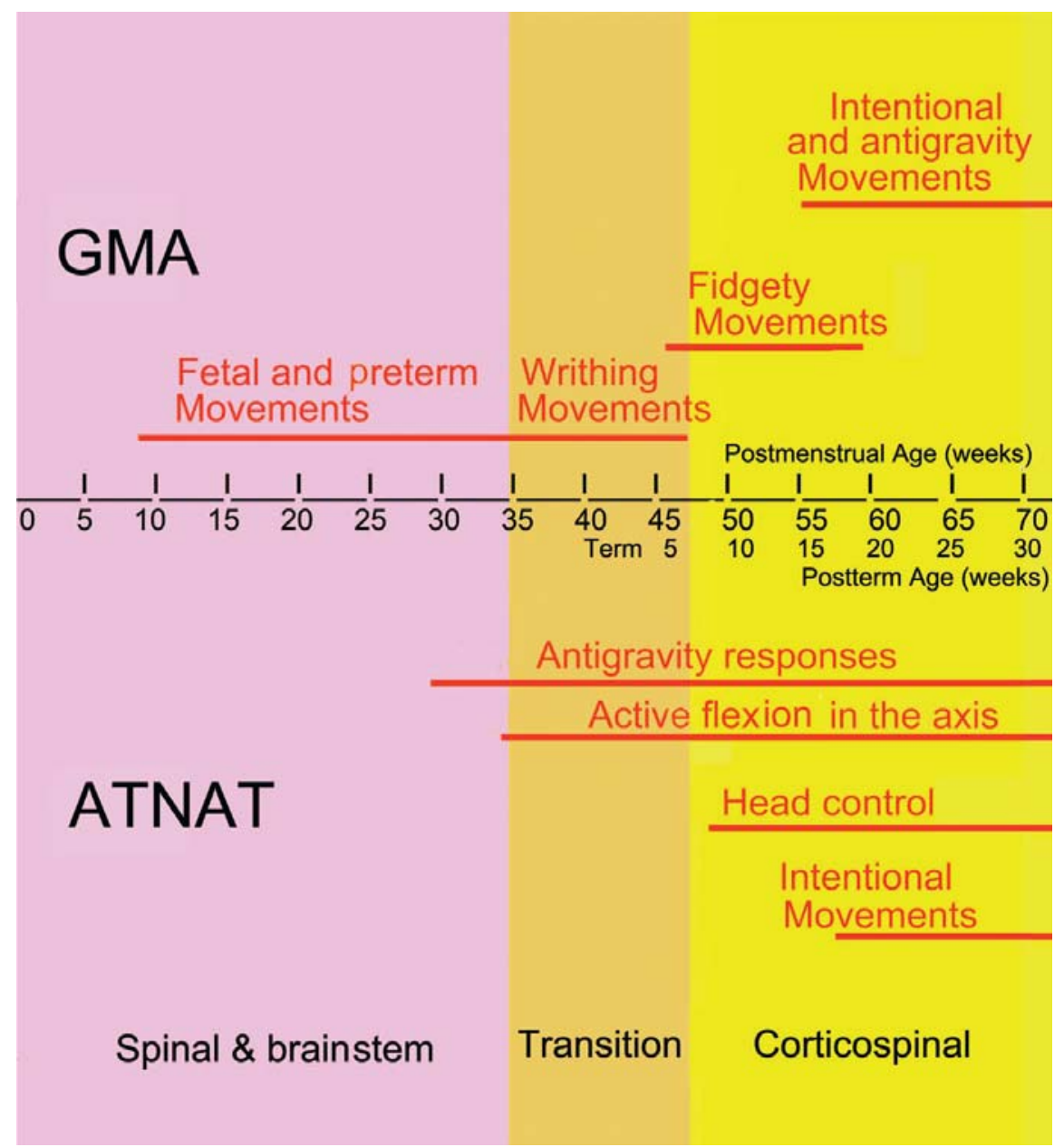

Fig. 12 Neuromaturative agenda for clinicians with the GMA and the ATNAT

The transition phase is identified by writhing movements when using GMA and by flexor tone in the axis when using ATNAT. Later, fidgety movements when using GMA and head control when using ATNAT occur when corticospinal control takes over the brainstem control.

NB: weeks indicated in the ATNAT do not represent the beginning of myelination but the time at which the clinician is able to test the activity of the neonate.

phase from around 34-36 PM weeks to 6-8 PT weeks: the GM A explores this transition through writhing movements while the ATNAT mainly uses the active tone in the flexor muscles of the body axis and active abduction of the thumbs.

\section{EXPECTATIONS AND LIMITS OF FETAL NEUROLOGY}

\section{Expectations}

Throughout this chapter devoted to methodology in the rapidly changing field of neonatal neurology, we have tried to combine experience and reason. We have chosen to compare our own assessment, belonging to the so-called "classical" school, with the GM A , in which we have little personal experience. We have therefore tried to stay as close as possible to the original writings, hence our quotations taken from the texts of Prechtl and other colleagues. During our readings, we have noticed the stereotypical way in which the classical assessment is labelled "reflex neurology", based on limited references confined to A ndré-Thomas and Peiper taken from the early sixties. Those two researchers were great clinicians but did not have access to the amazing recent advances in neurosciences. M oreover, their research on automatic walking ${ }^{12,60}$ is still current, as shown by the number of publications concerning this fascinating primary locomotion. For instance, recent experiments ${ }^{16}$ argue in favor of a rudimentary coupling present at birth between optical flow and locomotion. Such findings demonstrate that the infant's behavior is differentiated in line with the task at hand.

Throughout these methodological comparisons we have tried to establish links between the two approaches; we were struck by the fact that the goal of each approach is exactly the same and deals with the devel opment of early markers indicating 
From Neonatal to Fetal Neurology: Some Clues for Interpreting Fetal Findings

impairment of the upper structures of the brain. In this respect, current data show that any type of assessment is good enough to define optimality on the one hand and severe impairment on the other hand (as well as mothers, caregivers ... or radiologists with fetal IRM !). In between these two extremes, they face the same challenge, with the risk that early intervention in children who will later suffer from developmental disabilities is postponed.

\section{Limits}

Immaturity of the neonatal brain constitutes a limit in itself. The motor function, being the first to mature, is the first to provide the clinician with clues. Higher functions, in particular language and other cognitive functions, will develop later. However, recent researchers give credit to the brainstem for controlling exceedingly rudimentary learning-related cognitive-like activity. ${ }^{40}$ At present, the anticipation of late emerging developmental disabilities remains difficult even though early motor dysfunction has repeatedly been associated with a higher risk of intellectual deficiency or other learning disabilities. ${ }^{33,37,56,63}$ Despite our modest recent contribution to the domain of prediction, ${ }^{29}$ further studies on well-defined high risk populations with rigorous methodology that aim to demonstrate these links are still needed. B esides neurological observations research is in process of including behavioral and stress/reactivity measures; feasibility and benefits have to be demonstrated. ${ }^{67}$

\section{CONCLUSION}

A t present, fetal neurology is supported by neonatal neurology. Obstetricians are wise enough to take from both methods described above the el ements they are able to transpose to fetal life. A comparative table of neonatal and fetal assessment is to be found elsewhere in this book. As for neonatal neurology, the future of fetal neurology will have to rely on short- and long-term follow-up studies to define the predictive value of the chosen items. Obstetricians will have to be as patient as pediatricians, to work, step by step, towards defining optimality and impairment. They will have to be very careful when deciding to interrupt pregnancies; at the time being, such decisions are restricted to cases of very severe impairment. In line with the spectrum described above, they can expect to find more cases with moderate to mild abnormalities than cases with severe ones. However the most pleasant aspect for the echographer is to check fetal optimal ity as beautiful ly illustrated in various texts by K urjak's school. J ust as a newborn infant categorized as at risk of brain damage is competent enough to demonstrate CNS integrity from birth, a high risk fetus will soon be competent enough to demonstrate CNS integrity before birth.

\section{REFERENCES}

1. A miel-Tison C. Pediatric contribution to the present knowledge on the neurobehavioral status of infant at birth. In J M ehler, $R$ Fox (Ed): Neonate Cognition, beyond the Blooming Buzzing Confusion. Lawrence Erlbaum, Hillsdale NJ 1985.

2. Amiel-Tison $C$. Neurological assessment of the neonate revisited: a personal view. Dev M ed Child Neurol 1990;32,1109.

3. A miel-Tison $C$. Correlation between hypoxic-ischemic events during fetal life and outcome. In P A rbeille, D M aulik, R Laurini (Eds): Fetal Hypoxia. Parthenon, L ancs, UK 1999.

4. A miel-Tison $C$. Clinical assessment of the infant nervous system. In ML Levene, FA Chervenak, M Whittle (Eds): Fetal and Neonatal Neurology and Neurosurgery (3rd edn). Churchill Livingston L ondon 2001 (4th edn in press).

5. A miel-Tison $\mathrm{C}$. Update of the A miel-Tison neurologic assessment for the term neonate or at 40 weeks corrected age. Pediatr Neurol 2002;27,196.

6. A miel-Tison C, Gosselin J. Neurological Development from Birth through 6 years. J ohn Hopkins U niversity Press, B altimore 2001.

7. A miel-Tison C, Gosselin J. The Amiel-Tison and Gosselin neurological assessment and its correlations with disorders of higher cerebral function. In PJ A ccardo (Ed): Developmental Disabilities in Infancy and Childhood (3rd edn). Paul H B rookes, B altimore 2007.

8. A miel-Tison C, Gosselin J, Infante-Rivard C 2002: H ead G rowth and Cranial A ssessment at N eurological Examination in Infancy. Dev M ed Child Neurol 2002;44,643.

9. A miel-Tison C, Gosselin J, K urjak A. Neurosonography in the second half of fetal life: a neonatologist's point of view. J Perinat M ed 2006;34,437.

10. A miel-Tison C, Gosselin J, Kurjak A. Three-dimension/fourdimensional ultrasonography to detect fetal brain damage. Neoreviews 2007;8,e425.

11. A miel-Tison C, G renier A. Est-ce ainsi que les enfants naissent ? Laffont, Paris 1984.

12. André-Thomas, A utgaerden S. Locomotion from pre- to postnatal life. The National Spastics Society, L ondon 1966.

13. A ndré-Thomas, Saint-A nne-Dargassies $S$. Etudes neurologiques sur le nouveau-né et le jeune nourrisson. Paris, M asson 1952.

14. A njari M, Srinivasan L, A llsop J M , Hajnal JV, Rutherford M A, Edwards $A D$, et al. Diffusion tensor imaging with tract-based spatial statistics reveals local white matter abnormalities in preterm infants. N euroimage 2007;35,1021.

15. Back SA : Perinatal white matter injury: the changing spectrum of pathology and emerging insignts into pathogenetic mechanisms. M ent Retard Dev Disabil Res Rev 2006;12,129.

16. B arbu-Roth $M, A$ nderson DI, D esprés A, Provasi J, Campos J] . Neonatal stepping in relation to terrestrial optic flow. Child Development, in press.

17. Billiards SS, Haynes RL, Folkerth RD, Trachtenberg FL, Liu LG, Volpe JJ, et al. Development of microglia in the cerebral white matter of the human fetus and infant. J Comp Neurol 2006;497,199.

18. Birnholz JC. Fetal behaviour and condition. In PW Callen (Ed): Ultrasonography in gynecology and obstetrics. Saunders: Philadelphia 1983. 
19. Bundy A C, L ane SJ, M urray EA. Sensory Integration: Theory and Practice (2nd edn). FA Davis: Philadel phia 2002.

20. Counsell SJ, B oardman JP. Differential brain growth in the infant born preterm: current knowledge and future devel opments from brain imaging. Semin Fetal N eonatal M ed 2005;10,403.

21. Counsell SJ, Dyet LE, Larkman DJ, Nunes RG, Boardman JP, Allsop J M , et al. Thalamo-cortical connectivity in children born preterm mapped using probabilistic magnetic resonance tractography. Neuroimage 2007;34,896.

22. de G raaf-Peters V B , Hadders-A I gra M. O ntogeny of the human central nervous system: what is happening when? Early Hum Dev 2006;82,257.

23. Deschênes G, G osselin J, Couture M , L achance C. Interobserver reliability of the A miel-Tison neurological assessment at term. Pediatr Neurol 2004;30,190.

24. Dyet LE, K ennea N, Counsell SJ, M aalouf EF, A jayi-O be M, Duggan PJ, et al. Natural history of brain lesions in extremely preterm infants studied with serial magnetic resonance imaging from birth and neurodevelopmental assessment. Pediatrics 2006;118,536.

25. Einspieler C, Prechtl HF. Prechtl's assessment of general movements: a diagnostic tool for the functional assessment of the young nervous system. M ent Retard Dev Disabil Res Rev 2005; 11,61.

26. Einspieler C, Prechtl HFR, B os A F, Ferrari F, Cioni G. Prechtl's method on the qualitative assessment of general movements in preterm, term and young infants. Clinics in Dev M ed 167. M ac Keith Press, L ondon 2004.

27. Ghosh A, Shatz CJ . A role for subplate neurons in the patterning of connections from thalamus to neocortex. Development $1993 ; 117,1031$.

28. Gosselin J: Certains aspects métrologiques de I'Examen neuromoteur complémentaire: Thèse de doctorat. U niversité de M ontréal, M ontréal 1993.

29. Gosselin J, A miel-Tison C. Évaluation neurologique de la naissance à 6 ans. $2^{\mathrm{e}}$ édition. Presses du CHUME Ste-J ustine, M ontréal and M asson, Paris 2007.

30. Gosselin J, Gahagan S, A miel-Tison C. The A miel-Tison Neurological Assessment at Term: conceptual and methodological continuity in the course of follow-up. Ment Retard Dev Disabil Res Rev 2005;11,34.

31. Grenier A. Expression of liberated motor activity (LMA) following manual immobilization of the head. In C A miel-Tison, A Grenier (Eds): Neurological Evaluation of the Newborn and the Infant. M asson, N ew Y ork 1983.

32. Grenier A. La motricité libérée du nouveau-né: ses prolongements au quotidien pour le confort et la surveillance neurologique. M édecine \& Enfance, Paris 2000.

33. Groen SE, de Blécourt AC, Postema K, Hadders-A Igra M. $G$ eneral movements in early infancy predict neuromotor development at 9 to 12 years of age. Dev Med Child Neurol 2005; 47,731.

34. Hadders-A Igra M. General movements: a window for early identification of children at high risk for developmental disorders. J Pediatr 2004;145,812.
35. Hadders-A Igra M . G eneral movement during prenatal and early postnatal life. In A K urjak, G A zumendi: The Fetus in Three Dimensions: Imaging, Embryology, and Fetoscopy. Informa Health Care, UK 2007.

36. Hadders-A Igra M. Putative neural substrate of normal and abnormal general movements. Neurosci Biobehav Rev 2007;31,1181.

37. Hadders-A Igra $M, M$ avinkurve-G roothuis $A M$, Groen $S E$, Stremmelaar EF, M artijn A, Butcher PR. Quality of general movements and the development of minor neurological dysfunction at toddler and school age. Clin Rehabil 2004;18,287.

38. Haynes RL, B orenstein N S, D esilva TM , Folkerth RD, Liu L G, Volpe J], et al. A xonal development in the cerebral white matter of the human fetus and infant. J Comp Neurol 2005;484,156.

39. Inder TE, W ells SJ , M ogridge NB, Spencer C, V olpe JJ. Defining the nature of the cerebral abnormalities in the premature infant: a qualitative magnetic resonance imaging study. J Pediatr 2003;143,171.

40. Joseph R. Fetal Brain Behavior and Cognitive Development. Dev Review 2000;20,81.

41. Kostovic I, J ovaov-M ilosevic N. The development of cerebral connections during the first 20-45 w eeks' gestation. Semin Fetal Neonatal Med 2006;11,415.

42. Kostovic I, Judas M.Prolonged coexistence of transient and permanent circuitry elements in the developing cerebral cortex of fetuses and preterm infants. Dev Med Child Neurol 2006; $48,388$.

43. K rishnan M L, Dyet LE, B oardman JP, K apellou O, A IIsop J M, Cowan $F$, et al. Relationship between white matter apparent diffusion coefficients in preterm infants at term-equival ent age and developmental outcome at 2 years. Pediatrics 2007;120,e604.

44. Kurjak A, Andonotopo W, Hafner T, Salihagic Kadic A, Stanojevic M, Azumendi $G$ et al: Normal standards for fetal neurobehavioral developments- Iongitudinal quantification by four-dimensional sonography. J Perinat M ed 2006;34,56.

45. Kurjak A, Pooh RK, M erce LT, Carrera J M, Salihagic-K adic A, Andonotopo W: Structural and functional early human development assessed by three-dimensional and fourdimensional sonography. Fertil Steril 2005;84,1285.

46. Kurjak A, Stanojevic M, A ndonotopo W, Salihagic-Kadic A, Carrera J M , A zumendi G: B ehavioral pattern continuity from prenatal to postnatal life: a study by four-dimensional (4D) ultrasonography. J Perinat M ed 2004;32,346.

47. Lawrence DG, K uyppers HG J M : The functional organization of the motor system in the monkey: I. The effects of bilateral pyramidal lesions. Brain 1968;91,1.

48. Lawrence DG, K uyppers HGJM. The functional organization of the motor system in the monkey: I. The effects of lesions of the descending brainstem pathways. B rain 1968;91,15.

49. Liley AW. The foetus as a personality. A ust NZ J Psychiatry $1972 ; 6,99$.

50. Limperopoulos C, du Plessis AJ. Disorders of cerebellar growth and development. Curr Opin Pediatr 2006;18,621.

51. Limperopoulos C, Soul JS, Gauvreau K, Huppi PS, Warfield SK, Bassan $\mathrm{H}$ et al: Late gestation cerebellar growth is rapid and impeded by premature birth. Pediatrics 2005;115,688. 
52. Limperopoulos C, Soul JS, Haidar H, Huppi PS, Bassan H, Warfield SK, et al. Impaired trophic interactions between the cerebellum and the cerebrum among preterm infants. Pediatrics $2005 ; 116,844$

53. Malamateniou C, Counsell SJ, Allsop JM, Fitzpatrick JA, Srinivasan $L$, Cowan $F M$, et al. The effect of preterm birth on neonatal cerebral vasculature studied with magnetic resonance angiography at 3 Tesla. Neuroimage 2006;32,1050.

54. M cQuillen PS, Ferriero DM . Perinatal subplate neuron injury: implications for cortical development and plasticity. B rain Pathol 2005;15,250.

55. M ewes AU, Hüppi PS, Als H, Rybicki FJ, Inder TE, M cA nulty $G B$, et al. Regional brain development in serial magnetic resonance imaging of low-risk preterm infants. Pediatrics 2006;118,23.

56. Nakajima $Y$, Einspieler $C, M$ arschik PB, B os AF, Prechtl HF. Does a detailed assessment of poor repertoire general movements help to identify those infants who will develop normally? Early Hum Dev 2006;82,53.

57. Neisser U. Two perceptually given aspects of the self and their development. Developmental Review 1991;11,197.

58. Paro-Panjan D, N eubaues D, K odric J, B ratanic B. A miel-Tison neurological assessment at term age: clinical application, correlation with other methods, and outcome at 12 to 15 months. Dev M ed Child Neurol 2005;47,19.

59. Paro-Panjan D, Sustersic B, N eubauer D. Comparison of two methods of neurologic assessment in infants. Pediatr Neurol 2005;33,317.

60. Peiper A. Cerebral function in infancy and childhood (translation of the 3rd revised German edition by Nagler B and Nagler $\mathrm{H}$. Consultants Bureau, N ew Y ork 1963.

61. Prechtl HFR. Continuity and change in early neural development. In: HFR Prechtl: Continuity of N eural Functions from Prenatal to Postnatal Life. M acK eith Press, London, 1984.
62. Prechtl HFR. Qualitative changes of spontaneous movements in fetus and preterm infant are a marker of neurological dysfunction. Early Hum Dev 1990;23,51.

63. Prechtl HF, Einspieler C, Cioni G, Bos A F, Ferrari F, Sontheimer $D$. A n early marker for neurol ogical deficits after perinatal brain lesions. Lancet 1997;349,136.

64. Rutherford M, Counsell S, Allsop J, B oardman J, Kapellou O, Larkman $D$, et al. Diffusion-weighted magnetic resonance imaging in term perinatal brain injury: a comparison with site of lesion and time from birth. Pediatrics 2004;114,1004.

65. Saint-A nne Dargassies S. N eurological D evel opment in the FullTerm and Premature N eonate. Elsevier, A msterdam 1977.

66. Salihagic-Kadic A, M edic M, Kurjak A. Recent advances in neurophysiology. In: K urjak A, A zumendi $G$ (Eds): The Fetus in Three Dimensions: Imaging, Embryology, and Fetoscopy. Informa Health Care, UK 2007.

67. Salisbury AL, D uncan Fallone M , L ester B M . N eurobehavioral assessment from fetus to infant: the NICU Network Neurobehavioral Scale and the Fetal Neurobehavioral Coding Scale. M ent Retard Dev Disabil Res Rev 2005;11,14.

68. Sarnat HB. A natomic and physiologic correlates of neurologic development in prematurity. In HB Sarnat: Topics in neonatal neurology. Grune and Stratton, N ew Y ork 1984.

69. Suster $M L, B$ ate M. Embryonic assembly of a central pattern generator without sensory input. N ature 2002;416,174.

70. V olpe JJ. Subplate neurons- missing link in brain injury of the premature infant? Pediatrics 1996;97,112.

71. Volpe JJ. Cerebral white matter injury of the premature infantmore common than you think. Pediatrics 2003;112,176.

72. Volpe JJ. Encephalopathy of prematurity includes neuronal abnormalities. Pediatrics 2005;116,221. 